\title{
DIALOGANDO SOBRE O COTIDIANO ESCOLAR: FRONTEIRAS NÃO TÃO SECRETAS
}

\author{
FATIMA RAMALHO LEFONE*
}

\begin{abstract}
RESUMO
As reflexões ora apresentadas são inquietações alusivas às questões cotidianas vividas no chão da escola, sentidas dia a dia, tecidas e percebidas, sem a intenção de denominá-las, apenas repensar sobre a (in) visibilidade de ser e fazer, de modos certos ou incertos, mas de forma que possamos considerar os sujeitos humanos constituídos no espaço escolar. Objetivamos, para além das questões técnicas e tarefeiras, anunciar os sujeitos, suas vidas, seus valores, crenças, sentidos, significados e suas formas relacionais como vias fronteiriças, que constroem cotidianos autorreguladores por meio da migração conceitual e a partir de sua auto-hetero-eco ${ }^{1}$ capacidade transformadora.
\end{abstract}

Palavras-chave: Escola. Cotidiano. Complexidade. Fronteiras.

\begin{abstract}
The thoughts presented in this study concern everyday issues experienced at school, felt on a daily basis, woven and noticed. However, we do not intend to name them, but only to rethink

* Mestranda na Universidade Metodista de São Paulo. Orientadora: Prof ${ }^{a}$. Dr ${ }^{a}$. Norinês Panicacci Bahia. Projeto de Pesquisa: O protagonismo do diretor de escola em interface com a formação continuada de professores.

1 Nota da autora: A expressão auto-hetero-eco capacidade transformadora compreende que os sujeitos estabelecem as relações a partir de sua subjetividade, mas as constroem em interação com a diversidade e multiplicidade de outros sujeitos. Esse processo ocorre em um sistema (eco) e o movimento emergente desse processo, ou seja, a capacidade transformadora principia pela migração conceitual, resultando em outras formas de ser e fazer.
\end{abstract}


of the (in)visibility of being and doing, of certain or uncertain ways, so that we can consider human subjects as formed in school space. Beyond technical and task-like issues, we also intend to announce the subjects, their lives, values, beliefs, senses, meanings and their relational forms as border-like paths that build self-regulating everyday activities through the conceptual migration and from their self-hetero-eco ${ }^{2}$ transforming capacity.

Key-words: School. Quotidian. Complexity. Borders.

\section{INTRODUÇÃO}

Pensar no espaço escolar nos leva a refletir sobre as estruturas sistematizadas, impostas e predeterminadas, a respeito dos equipamentos físicos sempre presentes de concretudes de cores frias, muitas vezes em tons cinza, como estereótipos da ordem, do padrão, do modelo, do instituído, que também compreendemos enquanto constituição de um contexto.

Talvez as mudanças ocorram, e a vida corra apesar das instituições, dos tons de cinza, das sistematizações e das fragmentações. Sabedores somos da impermanência das instituições e dos cotidianos. A impermanência é um grande benefício à vida dos sujeitos e seus cotidianos, é o movimento para além da estagnação.

A complexidade sempre está presente, seja no velho ou no novo modelo de ser, de fazer e estar, mesmo que invisível, mas presente e latente.

A patologia da razão é a racionalização que encerra o real num sistema de ideias coerente, mas parcial e unilateral, e que não sabe que uma parte do real é irracionalizável, nem que a racionalidade tem por missão dialogar com o irracionalizável. Ainda estamos cegos ao problema da complexidade (MORIN, 2015, p. 15).

2 Note: The expression. Self-hetero-eco transforming capacity understands that the subjects establish relations from their subjectivity on, but they build it in interaction with the diversity and multiplicity of other subjects. This process takes place in a system (eco), and the emerging movement of this process, that is, their transforming capacity starts with the conceptual migration thus resulting in other ways of being and doing. 
O cotidiano presente nos espaços escolares são condicionantes complexos, são movimentos vivos que anunciam todas as formas de saberes e que, muitas vezes, em nome das ciências racionais, são desconsiderados, e esse espaço que poderia ser uma via de compartilhamento de policonhecimentos, torna-se um lugar estático de aparente passagem, com características simplistas de transitoriedade.

O sentido não assume o significado do real espaço e a presença de ser não se consolida em sujeitos aprendentes.

Os lugares, então, são tomados por sujeitos que não se assumem aprendentes: apenas reproduzem e acumulam informações.

Por conseguinte, como educadores, pensemos em cotidianos escolares fortalecidos por sujeitos conscientes em interface com o pensamento complexo, não sofrendo da cegueira errante, mas admitindo, em suas práticas, a riqueza das incertezas e saboreando a riqueza da formação.

\section{O COTIDIANO INVISÍVEL: FRONTEIRAS NÃO TÃO SECRETAS}

A escola e o seu cotidiano são espaços ampliados de movimentação complexa, por mais que queiramos impor o linearismo, novas formas de ser e fazer se instituem no locus escolar e anunciam os cotidianos invisíveis em que as fronteiras não são tão secretas. São apelos que correm por diversas vias e que, se não são levados em consideração, são traduzidos como patológicos e vistos como desordem.

Mesmo sentindo os sinais ditos das patologias e traduzidos como indisciplina, comportamentos inadequados, falta de compromissos, entre outros, os reprodutores do sistema negam-se a investigar as causas e preferem adotar a invisibilidade aos sujeitos que assim se encontram.

Nas situações de invisibilidade, ignoramos:

...os conjuntos complexos, as interações e retroações entre partes e todo as entidades multidimensionais, os problemas essenciais (MORIN, 2015, p. 13). 
Quando nos referimos aos sujeitos que constituem o espaço escolar, é fundamental que entendamos que o nosso recorte se dá aos docentes, discentes e equipe gestora, não em demérito dos demais segmentos. Para além da limitação, também, consideramos que não são apenas invisíveis os discentes, como se só a eles se dirigisse a incompreensão do sistema estruturado, mas a todos os sujeitos que, de uma forma ou de outra, possuem um olhar, um fazer, uma práxis que caminha para além do paradigma linear e que, mesmo sem denominar, compreendem que novas concepções emergem.

Como poderíamos, pois, tornar visíveis os sujeitos que talvez sintam nas fronteiras outras possibilidades de caminhos exceto os propostos ou impostos?

Reconhecer os princípios da complexidade é um excelente movimento que possibilitaria trilhar essa via, e esse é um exercício interessante para nós, educadores:

\section{Princípios da Complexidade ${ }^{3}$}

\begin{tabular}{|l|l|}
\hline $\begin{array}{l}\text { 1. Princípio } \\
\text { Organtêmico ou }\end{array}$ & $\begin{array}{l}\text { Que liga o conhecimento das partes ao conheci- } \\
\text { mento do todo. } \\
\text { A ideia sistêmica, oposta à ideia reducionista, é que } \\
\text { "o todo é mais do que a soma das partes". }\end{array}$ \\
\hline $\begin{array}{l}\text { 2. Princípio } \\
\text { Hologrâmico }\end{array}$ & $\begin{array}{l}\text { Põe em evidência esse aparente paradoxo das orga- } \\
\text { nizações complexas, em que não apenas a parte está } \\
\text { no todo, como o todo está inscrito na parte. Assim, } \\
\text { cada célula é uma parte de um todo - o organismo } \\
\text { global -, mas também o todo está na parte: a totali- } \\
\text { dade do patrimônio genético está presente em cada } \\
\text { célula individual; a sociedade está presente em cada } \\
\text { indivíduo, enquanto todo, através de sua linguagem, } \\
\text { sua cultura, suas normas. }\end{array}$ \\
\hline $\begin{array}{l}\text { 3. Princípio do } \\
\text { circuito retroa- } \\
\text { tivo }\end{array}$ & $\begin{array}{l}\text { Rompe com o princípio da causalidade linear: a causa } \\
\text { age sobre o efeito, e o efeito age sobre a causa, como } \\
\text { no sistema de aquecimento, em que o termostato } \\
\text { regula o andamento do aquecedor. Esse mecanismo } \\
\text { de regulação permite, aqui, a autonomia térmica de } \\
\text { um apartamento em relação ao frio externo. }\end{array}$ \\
\hline
\end{tabular}

Quadro elaborado a partir de informações contidas em Morin, 2015, p. 93-97. 


\begin{tabular}{|l|l|}
\hline $\begin{array}{l}\text { 4. Princípio do } \\
\text { circuito recursivo }\end{array}$ & $\begin{array}{l}\text { Ultrapassa a noção de regulação com as de autopro- } \\
\text { dução e auto-organização. É um circuito gerador } \\
\text { em que os produtos e os efeitos são, eles mesmos, } \\
\text { produtores e causadores daquilo que os produz. }\end{array}$ \\
\hline $\begin{array}{l}\text { 5. Princípio da } \\
\text { autonomia / de- } \\
\text { pendência (auto- } \\
\text {-organização) }\end{array}$ & $\begin{array}{l}\text { Os seres vivos são seres auto-organizadores, que } \\
\text { nespendem energia para manter sua autonomia. } \\
\text { Como têm necessidade de retirar energia, infor- } \\
\text { mação e organização de seu meio ambiente, sua } \\
\text { autonomia é inseparável dessa dependência; é por } \\
\text { isso que precisam ser concebidos como seres au- } \\
\text { toecoorganizadores. }\end{array}$ \\
\hline $\begin{array}{l}\text { 6. Princípio dia- } \\
\text { lógico }\end{array}$ & $\begin{array}{l}\text { Une dois princípios ou noções que deviam excluir- } \\
\text {-se reciprocamente, mas são indissociáveis em uma } \\
\text { mesma realidade. }\end{array}$ \\
\hline $\begin{array}{l}\text { 7. Princípio da } \\
\text { reintrodução do } \\
\text { conhe cimento } \\
\text { em todo conhe- } \\
\text { cimento }\end{array}$ & $\begin{array}{l}\text { Opera a restauração do sujeito e revela o problema } \\
\text { todo conhecimento é uma reconstrução/tradução } \\
\text { feita por uma mente/cérebro, em uma cultura e } \\
\text { época determinadas. }\end{array}$ \\
\hline
\end{tabular}

A percepção desses operadores nos permite um olhar diferenciado sobre a realidade no chão da escola, religa-nos às coisas humanas, promovendo a junção com os princípios e as finalidades da educação, que são aspectos para além das formalidades e, portanto, devem caminhar em busca da reorganização humana e sua qualidade planetária.

O cotidiano escolar é o movimento propulsor e cíclico do fazer real na escola, não há currículos e projetos que se materializem sem o alinhamento aos sujeitos que permeiam o espaço escolar.

Os recursos da dialogicidade, da recursividade e do princípio hologramático são operadores iniciais, capazes de auxiliar nos diagnósticos, na seleção crítica de conteúdos, nas múltiplas possibilidades avaliativas e em todo processo formativo, considerando sempre a força presente no cotidiano, nas relações fronteiriças tecidas não tão secretamente pelos sujeitos nos espaços escolares. 


\section{COTIDIANO ESCOLAR - COMPLEXIDADE - ECOFORMAÇÃO}

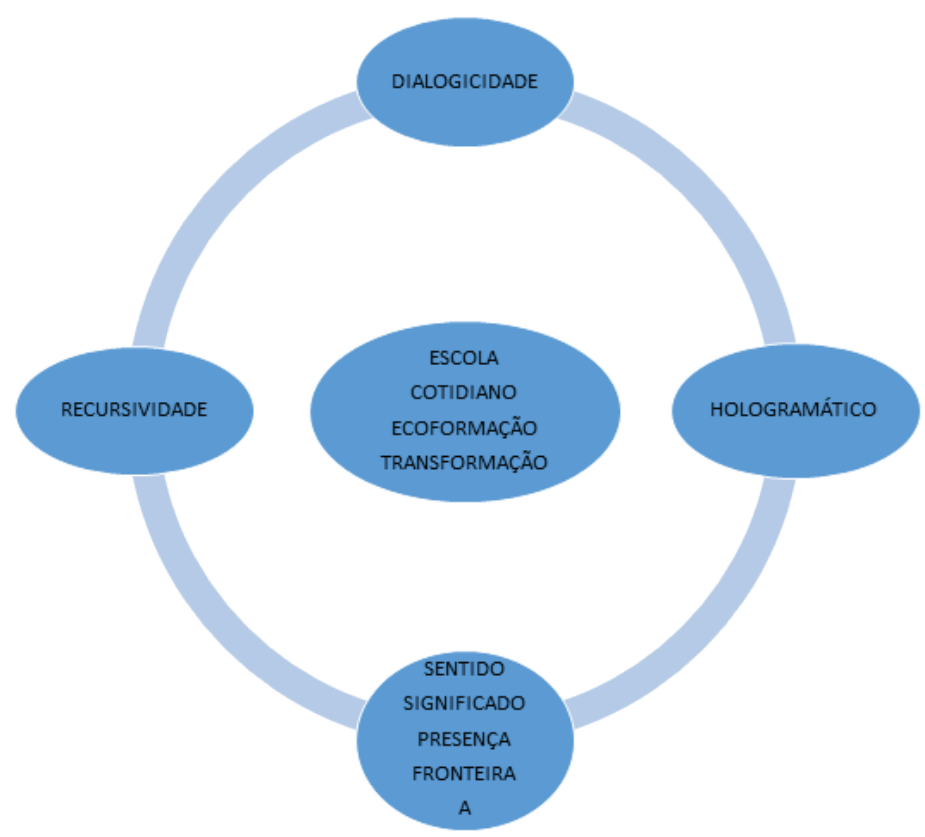

$\mathrm{Na}$ teia complexa da atualidade, das novas demandas, de ressignificações múltiplas no campo educacional, o conhecimento real é uma das vias que emergem para que possamos ter qualidade de vida, para que a vida humana se torne de fato mais humana. Nesse contexto, a escola assume papel de fundamental relevância, é nela que ocorrem as possibilidades de transformações, é nela que, apesar dos antagonismos - e graças a eles - se reproduzem as sistematizações, mas que também surgem os movimentos sistêmicos-críticos-reflexivos, que libertam os sujeitos.

A complexidade é mais uma ferramenta de junção de que podemos nos valer em contribuição para compreender que os cotidianos são carregados de crenças, valores, lendas pessoais, contextos históricos, sociais, políticos, desejos, sonhos, histórias de gentes diferentes, que, mesmo sem saber, buscam um espaço 
com causa-efeito que se revele em sentimento de pertença, de acolhimento e de empoderamento nessa via chamada escola.

\section{CONSIDERAÇÕES FINAIS}

O cotidiano é fator relevante no espaço escolar, uma vez que nele se constroem as relações objetivas e subjetivas de todos os sujeitos que constituem o chão da escola.

Esse é um fato que ninguém ignora, mas que também não conhece ou reconhece, conferindo àquele a devida importância, como análise efetiva de seus efeitos nas esferas da escola.

Seja no currículo, seja nos projetos, nas intenções registradas, até nos combinados, o tal cotidiano fica quase invisível e é somente sentido quando se revela e se traduz em seus significados.

O que para os sujeitos tem sentido? Que significações possuem das práticas escolares?

Sem a análise crítica reflexiva dessas questões, vivemos no limite, e os cotidianos vivem na quase invisibilidade. Isso não quer dizer que não sejam sentidos ou que não existam, apenas que não são reconhecidos, e as consequências são traduzidas na fragmentação do conhecimento que, muitas vezes, nem se efetivam enquanto saberes: ficam na reprodução mecânica e descontextualizada.

Que formação estamos propondo? Que sujeitos estamos formando? A serviço de quem e para quem formamos?

São velhas questões, mas que sempre estarão presentes na seara educacional, enquanto não consolidarmos quem de fato consideramos em formação para a vida sistêmica em movimento, em que as ações possibilitem ultrapassar os limites rumo a fronteiras.

Por meio da complexidade, podemos vislumbrar multidimensões que nascem das microdimensões, da ecoformação, dos cotidianos não invisíveis promovidos por espaços escolares aprendentes, emancipatórios e fronteiriços. 


\section{REFERÊNCIAS}

GUMBRECHT, H. U. Produção de presença: o que o sentido não consegue transmitir. Rio de Janeiro: Contraponto: Ed. PUC-Rio, 2010.

MORIN, E. A cabeça bem feita: repensar a reforma, reformar o pensamento, 22. ed. Rio de Janeiro: Bertrand Brasil, 2015.

MORIN, E. Ensinar a viver: manifesto para mudar a educação. Porto Alegre: Sulina, 2015.

MORIN, E. Introdução ao pensamento complexo, 5. ed. Porto Alegre: Sulina, 2015. 